\title{
Evaluation of structural, optical and physical properties of polyurethane composites doped with metal alkoxides
}

\author{
MARZIEH NADAFAN*, JAVID ZAMIR ANVARI \\ Department of Physics, Faculty of Science, Shahid Rajaee Teacher Training University, Tehran, Lavizan, P.O. Box \\ 16788-15811, I.R. Iran
}

\begin{abstract}
In this research, polyurethane (PU)/tetraethyl orthosilicate (TEOS) composite was prepared via one-step polymerization method using different concentrations of TEOS in PU. The structural, optical and physical properties of PU composite were characterized by SEM imaging, FT-IR spectroscopy, water uptake, Raman spectroscopy and optical microscopy imaging of synthesized samples. The SEM results showed that by adding TEOS to the PU, the cell and window size of synthesized samples decreased. This result was also observed in the optical micrographs. The bonding characteristics of PU/TEOS composites were analyzed using Raman and FT-IR spectra. According to the FT-IR spectra, the degree of phase separation (DPS) and hydrogen bonding index, R, in $800 \mu \mathrm{l}$ TEOS/PU had the highest R and DPS factors. By adding different concentrations of TEOS to PU, the apparent density decreased but the real density increased. The total, open and closed porosity of the synthesized samples were calculated. At low loading of TEOS in PU, the open porosity of the samples increased. The PU/TEOS composites may be promising candidates for absorbing sound.
\end{abstract}

Keywords: polyurethane; FT-IR spectroscopy; Raman spectroscopy; porosity; density; SEM analysis

\section{Introduction}

In some industrial products, polyurethanes (PUs) are widely used as raw materials [1, 2]. The coatings, fibers, thermoset foams, thermoplastic elastomers and dozens of other industries depend on PUs [1-4]. Scientists today are interested in producing high-performance polyurethane (PU). Changing the size, weight and type of soft and hard parts of PU or changing the chemical composition of PU chain can affect the PU morphology.

Organic and inorganic hybrid compounds have the advantages of organic polymers and minerals, such as flexibility, hardness, high thermal stability, etc. Moreover, these properties depend on various types of inorganic or organic fillers [5-7]. The inorganic fillers cannot improve the polymer toughness or increase their fragility $[8,9]$. Thus, it would be better to replace inorganic filler with an organic one.

*E-mail: M_naddafan@yahoo.com
Some types of metal alkoxides, such as tetraethoxysilane (TEOS) can be replaced with $\mathrm{SiO}_{2}$ as an inorganic filler instead of organic one. The reasons for choosing TEOS are as follows: it is the most typical silica-organic precursor, it is easily purified and has slow and controllable rate of reaction. Unlike most of organic polymers, PU/TEOS composites have high stability at low temperature, and excellent physical properties.

This study aims to evaluate the presence of TEOS in PU matrix by considering and focusing on its optical and structural properties. The optical micrograph, scanning electron microscopy (SEM) imaging, Fourier transform infrared (FT-IR) spectra and Raman backscattering spectroscopy have been used to analyze the optical and structural properties of the synthesized samples. The physical and structural properties were investigated by water uptake, calculation of real or true density, bulk or apparent density and porosity of the synthesized samples. The degree of phase separation (DPS) and the hydrogen bonding index, $\mathrm{R}$, in the PU/TEOS were investigated using FT-IR spectra. 


\section{Experimental}

\subsection{Materials}

Tetraethyl orthosilicate (TEOS, $\mathrm{C}_{8} \mathrm{H}_{20} \mathrm{O}_{4} \mathrm{Si}$, $99 \%$ ) was purchased from Merck. Diphenyl methane diisocyanate (MDI, $\rho=1.23 \mathrm{~g} / \mathrm{cm}^{3}$ ), polyether polyol (SROC: semi-rigid open cell density $=1.1 \mathrm{~g} / \mathrm{cm}^{3}$ ) with blowing agent, catalyst, and surfactant were acquired from Exxon Panah Co., Ltd., Tehran, Iran. Deionized water was used as the blowing agent.

\subsection{Preparation of blank PU}

A one-step system has been used for PU foam preparation [8]. For blank PU, MDI and polyether polyol were mixed at $1: 1$ ratio at $3000 \mathrm{rpm}$ for about $12 \mathrm{~s}$ in an open cylindrical mold at room temperature. No heating was necessary [8]. The synthesized samples were stored in a liquid nitrogen gas and cut into slices of $1 \mathrm{~mm}$ diameter for the analysis.

\subsection{Preparation of PU/TEOS}

Four different amounts of TEOS $200 \mu \mathrm{l}, 400 \mu \mathrm{l}$, $600 \mu \mathrm{l}$ and $800 \mu \mathrm{l}(0.05$ Vol./Vol., 0.1 Vol./Vol., 0.15 Vol./Vol. and 0.2 Vol./Vol.) were individually dissolved in $2 \mathrm{ml}$ of the polyol. The dissolving was carried out under vigorous stirring for $15 \mathrm{~s}$ at $2500 \mathrm{rpm}$ until a homogenous solution was obtained. After that, MDI part was added to the solution by vortexing at $2500 \mathrm{rpm}$ for $5 \mathrm{~s}$ to $10 \mathrm{~s}$. When the sample was ready, the cover of the container of PU/TEOS was taken off. After $15 \mathrm{~s}$ to $20 \mathrm{~s}$, the reaction was carried out by foam formation in the samples. The ratio of polyol:MDI was 1 $(4 \mathrm{ml}): 1(4 \mathrm{ml})$. The freeze-fractured surface of all synthesized samples was cut into slices of $1 \mathrm{~mm}$ diameter.

\section{Results and discussion}

\subsection{Microscopic evaluation}

To determine the microstructural cell size of PU/TEOS foams, optical microscopy was used. The layers of the synthesized samples were cut with a sharp razor blade into circular slices of
$10 \mathrm{~mm}$ diameter and $1 \mathrm{~mm}$ thickness which was done in liquid nitrogen. So, the freeze-fractured surfaces were ready for examination. Optical micrographs were taken using an optical microscope (Nikon; TE 2000-S) in the transmission mode with $\times 40$ magnification.

Fig. 1 shows the transmitted optical microscopy images for PU containing TEOS with different concentrations. As shown in Fig. 1, with an increase in the amount of TEOS, the mean cell size of the PU/TEOS composites decreases.

\subsection{SEM analysis}

The synthesized samples were analyzed under SEM, Seron Technology-AIS2100 model after coating the samples with a thin layer of gold. According to Fig. 2, the differences between the PU/TEOS composites foams with TEOS content of $200 \mu \mathrm{l}$ to $800 \mu \mathrm{l}$ are shown. Close assessment of the cell struts indicates that the PU/TEOS composite foams have a microporous skeleton. The existence of microvoids in the microstructure of PU/TEOS reveals the chemical reactivition of TEOS with isocyanate monomer [9]. Some characteristics, such as the cell size $\mathrm{D}$, the window size $\mathrm{w}$, the window shape factor AR, and the strut thickness were determined by SEM imaging [10-12]. The cell diameter, the major axis of the window, the aspect ratio which represents the ratio between the length of the major axis and its perpendicular, the strut transverse length are denoted by $\mathrm{D}, \mathrm{w}, \mathrm{AR}$, and 1 , respectively. The average data correspond to a total of 40 cell sizes (D), 25 window sizes (w), 25 aspect ratios (AR) and 25 strut thicknesses (1) [10].

The parameters measured from the images are shown in Fig. 3 and summarized in Table 1. The cell and window size distributions are compared in Fig. 4 and Fig. 5. All data were compared at the $5 \%$ confidence level. In the structure specification, the data in Table 1 clearly show that the foams reflect the internal architecture of the corresponding specimen.

The SEM images with the cell size distribution histograms of the PU/TEOS composites are also presented in Fig. 6. Due to the apparent 

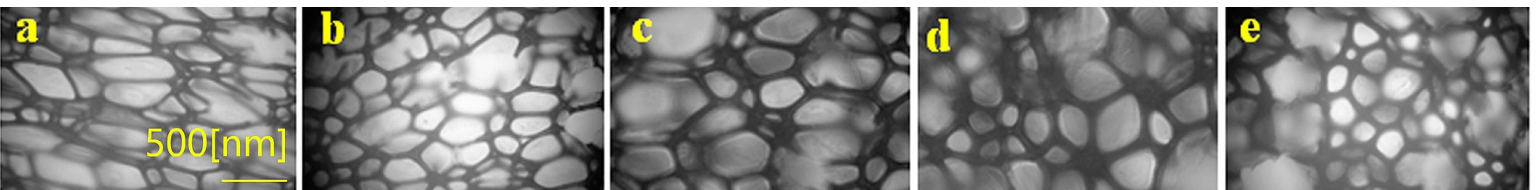

Fig. 1. Optical micrographs of PU foams with TEOS contents of (a) $0 \mu \mathrm{l}$, (b) $200 \mu \mathrm{l}$, (c) $400 \mu \mathrm{l}$, (d) $600 \mu \mathrm{l}$, and (e) $800 \mu 1$.

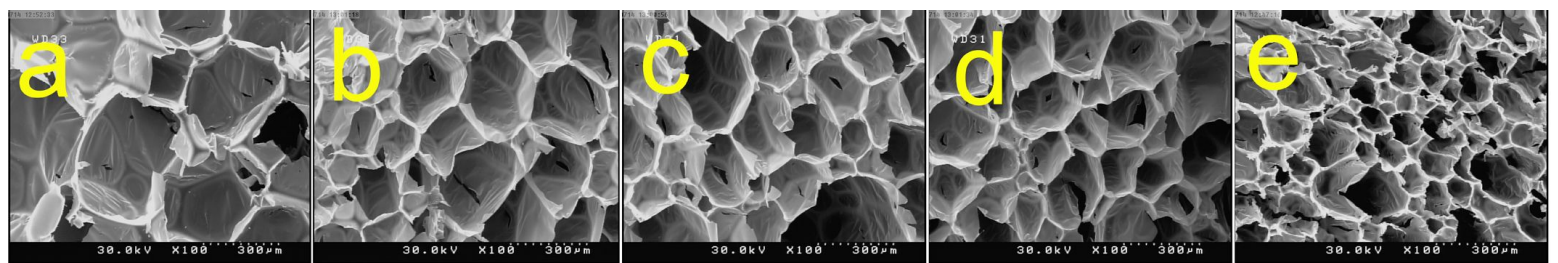

Fig. 2. SEM images of the PU foams with TEOS content of (a) $0 \mu \mathrm{l}$, (b) $200 \mu \mathrm{l}$, (c) $400 \mu \mathrm{l}$, (d) $600 \mu \mathrm{l}$, and (e) $800 \mu \mathrm{l}$.

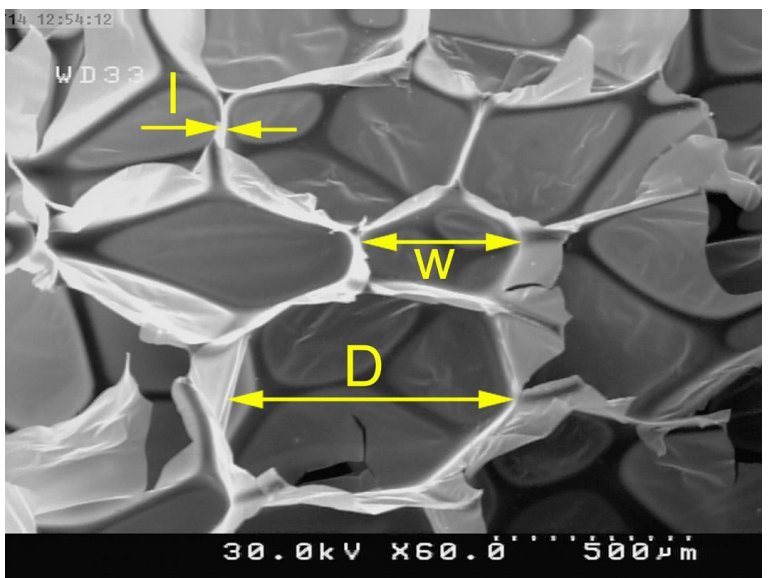

Fig. 3. SEM image of PU foams illustrating measured microstructural parameters: D (cell size), $\mathrm{w}$ (window size), and 1 (strut thickness).

behavior illustrated in Fig. 4 to Fig. 6, the average cell sizes of PU/TEOS composites are about $345 \mu \mathrm{m}, 225 \mu \mathrm{m}, 200 \mu \mathrm{m}, 155 \mu \mathrm{m}$ and $145 \mu \mathrm{m}$ for $0 \mu \mathrm{l}$ to $800 \mu \mathrm{l}$ TEOS in PU, respectively. It was found that the size of the cells decreased with an increase in the concentration of TEOS in the PU matrix. The main morphological results are shown in Table 1 and Fig. 4 to Fig. 6.

(i) The average cell and window size of pure PU foam is larger than those of PU/TEOS.

(ii) Although the window size distributions of PU/TEOS are finer and narrower than those of the

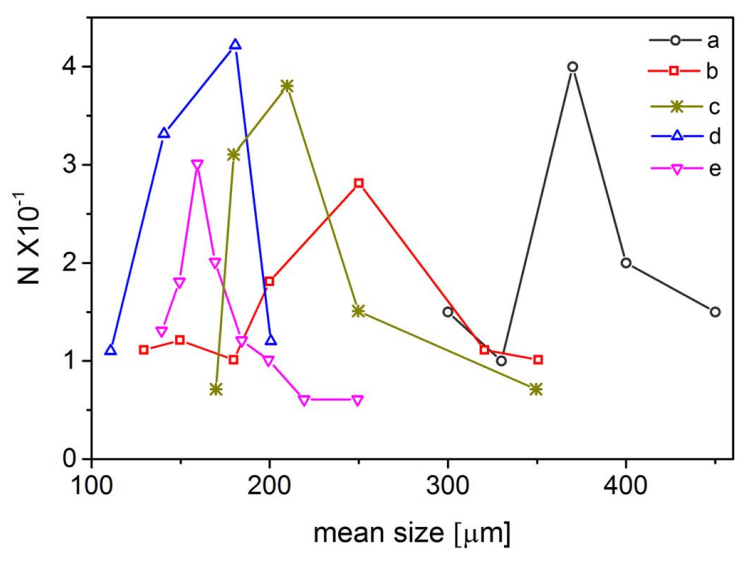

Fig. 4. Cell size distributions (number \%) of the PU foams with different TEOS contents of (a) $0 \mu \mathrm{l}$, (b) $200 \mu \mathrm{l}$, (c) $400 \mu \mathrm{l}$, (d) $600 \mu \mathrm{l}$, and (e) $800 \mu \mathrm{l}$.

pure PU, the cell size distribution of pure PU is narrower than those of the PU/TEOS.

(iii) The window elliptical shape in pure PU is more pronounced than that in PU/TEOS.

(iv) By adding TEOS into the polymer matrix from $200 \mu$ lo $800 \mu \mathrm{l}$ :

- The cell and window size distributions of PU/TEOS become coarser.

- The average cell and window sizes of PU/TEOS become coarser.

- The window shape in PU/TEOS becomes less elliptical. 


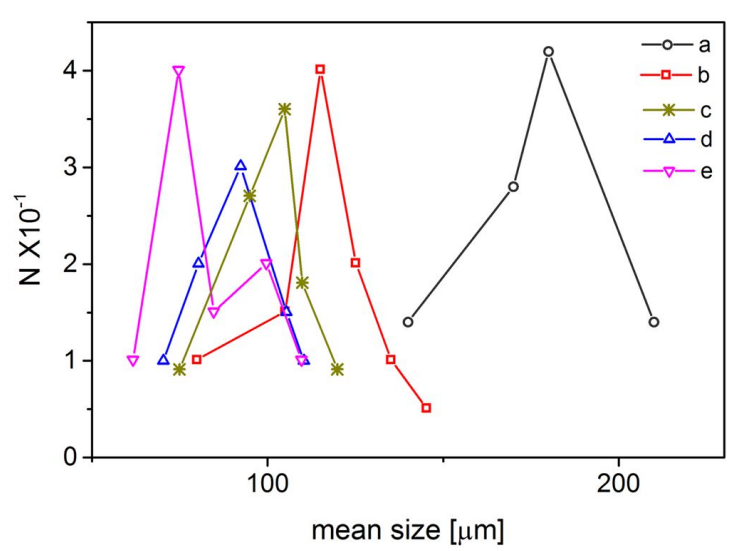

Fig. 5. Window size distributions (number \%) of the PU foams with different TEOS contents of (a) $0 \mu \mathrm{l}$, (b) $200 \mu \mathrm{l}$, (c) $400 \mu \mathrm{l}$, (d) $600 \mu \mathrm{l}$, and (e) $800 \mu \mathrm{l}$.

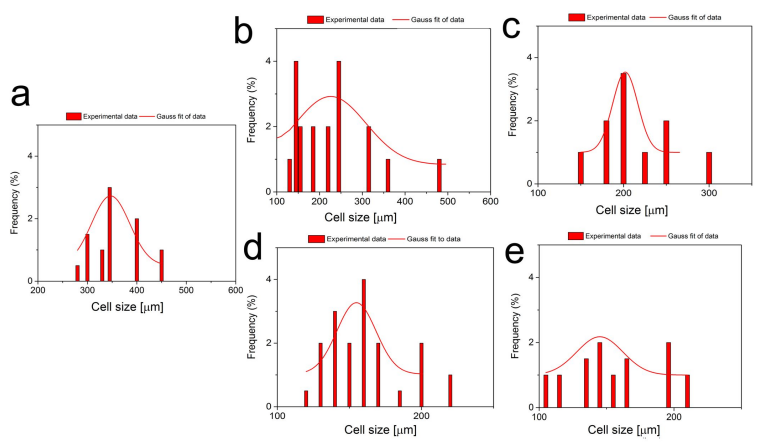

Fig. 6. Histograms of cell size distributions of the PU foams with TEOS content of (a) $0 \mu \mathrm{l}$, (b) $200 \mu \mathrm{l}$, (c) $400 \mu \mathrm{l}$, (d) $600 \mu \mathrm{l}$, and (e) $800 \mu \mathrm{l}$.

\subsection{FT-IR spectroscopy analysis}

FT-IR transmission spectra of the samples in a form of powder-pressed $\mathrm{KBr}$ pellets were collected by using a Thermo Nicolet Nexus 670 FT-IR spectrometer system with $4 \mathrm{~cm}^{-1}$ resolution and in the wave number range of $400 \mathrm{~cm}^{-1}$ to $3600 \mathrm{~cm}^{-1}$ at room temperature.

Fig. 7 shows the detailed FT-IR spectra of PU/TEOS composites. It is clear that all the spectra are similar, but there are some differences between them. After adding TEOS to PU matrix, some absorption peaks are created at $457 \mathrm{~cm}^{-1}, 1012 \mathrm{~cm}^{-1}$, and $1080 \mathrm{~cm}^{-1}$ in all PU/TEOS composites. These peaks are related to $\mathrm{Si}-\mathrm{O}-\mathrm{Si}$ bond rocking vibration [13], $\mathrm{Si}-\mathrm{O}-\mathrm{C}$ bonding [14], and asymmetric Si-O-Si stretching mode [15]. In all these spectra, the intensity of these peaks increases as a result of adding up to $800 \mu \mathrm{l}$ TEOS.

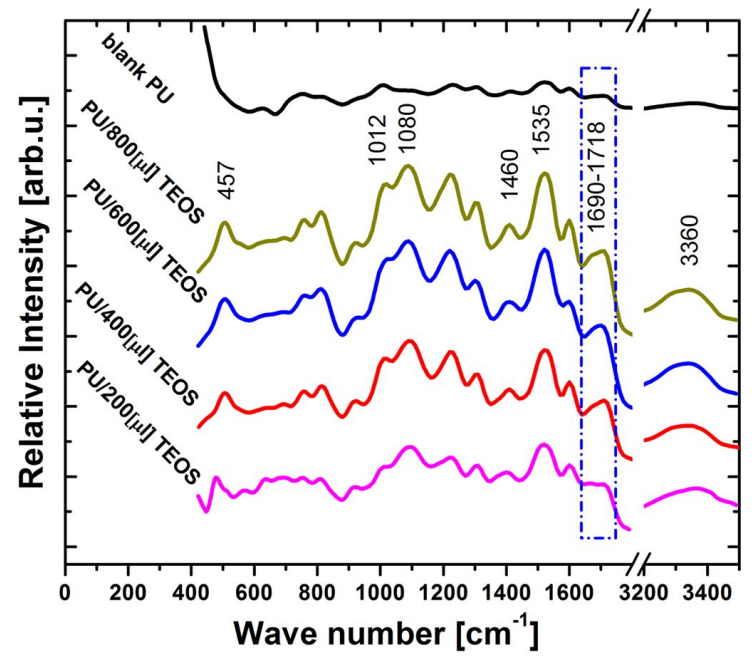

Fig. 7. FT-IR spectra of PU foams with different TEOS contents.

The intensities of the peaks at $1460 \mathrm{~cm}^{-1}$, $1535 \mathrm{~cm}^{-1}$, and $3360 \mathrm{~cm}^{-1}$ is connected with the secondary reaction between two main groups (urethane-isocyanate) [16], urethane $\mathrm{N}-\mathrm{H}$ bending [17], and $\mathrm{N}-\mathrm{H}$ bonds of urethane [18] in PU composite foams, respectively, which increase with the addition of TEOS into polymer matrix.

The fundamental factor for measuring physical properties of PU foam is the degree of phase separation (DPS). Xia et al. [19] examined the DPS by the Cooper method. He found two peaks at $1690 \mathrm{~cm}^{-1}$ and $1718 \mathrm{~cm}^{-1}$ which are related to the bonded carbonyl and free carbonyl groups [3]. The hydrogen bonding index, $\mathrm{R}$, is assigned to the ratio of absorption peak as $\mathrm{R}=\mathrm{A}_{\text {bonded }} / \mathrm{A}_{\text {free }}$, where $A_{\text {bonded }}$ is the absorbance peak intensity of $1690 \mathrm{~cm}^{-1}$ and $A_{\text {free }}$ is the absorbance peak intensity of $1718 \mathrm{~cm}^{-1}$. In our case, the hydrogen bonding index, R, and DPS decreased with addition of $600 \mu \mathrm{l}$ TEOS and began to increase with $800 \mu \mathrm{l}$ TEOS added into PU foams (Table 2). The results show that for the low loading of TEOS $(200 \mu \mathrm{l}$ to $600 \mu \mathrm{l})$ in PU foams, the TEOS prefers locating in 
Table 1. Summary of the microstructural parameters obtained on the foam sections (mean \pm standard deviation).

\begin{tabular}{ccccc}
\hline Foams & Cell size $\mathrm{d}[\mu \mathrm{m}]$ & Window size $\mathrm{w}[\mu \mathrm{m}]$ & $\begin{array}{c}\text { Strut thickness I } \\
{[\mu \mathrm{m}]}\end{array}$ & $\begin{array}{c}\text { Window aspect ratio } \\
\text { AR }\end{array}$ \\
\hline \hline Blank PU & $375 \pm 70$ & $180 \pm 50$ & $5 \pm 2$ & $1.40 \pm 0.16$ \\
$\mathrm{PU} / 200 \mu \mathrm{l}$ TEOS & $246 \pm 43$ & $123 \pm 23$ & $6 \pm 2$ & $1.38 \pm 0.23$ \\
$\mathrm{PU} / 400 \mu \mathrm{l}$ TEOS & $210 \pm 53$ & $108 \pm 28$ & $7 \pm 3$ & $1.37 \pm 0.26$ \\
$\mathrm{PU} / 600 \mu \mathrm{l}$ TEOS & $174 \pm 30$ & $90 \pm 21$ & $8 \pm 3$ & $1.35 \pm 0.31$ \\
$\mathrm{PU} / 800 \mu \mathrm{l}$ TEOS & $158 \pm 70$ & $53 \pm 16$ & $7 \pm 4$ & $1.33 \pm 0.17$ \\
\hline
\end{tabular}

the hard segment. However, in case of high loading, it is setting in the soft segment.

\subsection{Raman backscattering analysis}

Raman spectra of the samples were collected by using a Thermo Nicolet Almega dispersive microRaman spectrometer operating at $532 \mathrm{~nm}$ wavelength as the second harmonic of an Nd:YLF laser in a backscattering configuration.

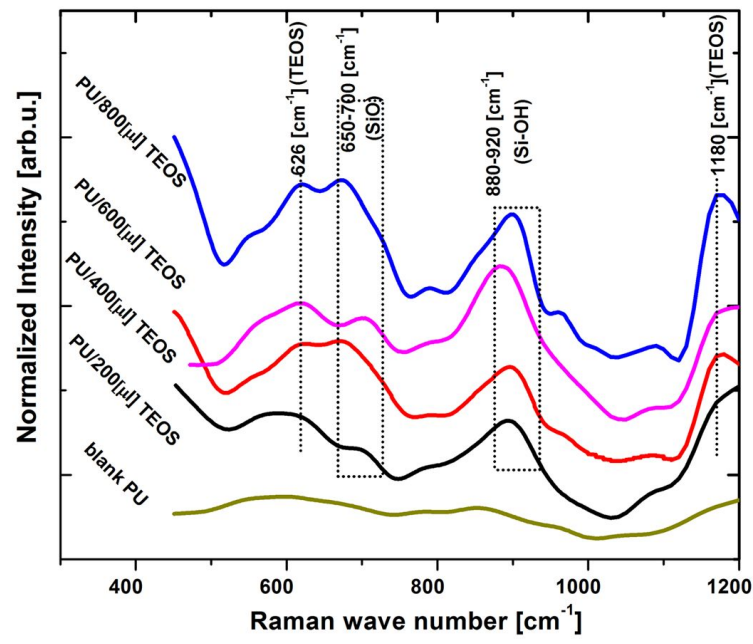

Fig. 8. Raman spectra of PU foams with different TEOS contents.

The measured Raman spectra of PU/TEOS are shown in Fig. 8. The Raman peaks at $626 \mathrm{~cm}^{-1}$ and $1180 \mathrm{~cm}^{-1}$ are related to the existence of TEOS which was observed in all PU/TEOS composites. The intensity of these peaks is increased by addition of more TEOS into PU matrix [13]. Thus, they are more intense the higher concentration of TEOS in PU. There is a band which is present in the $880 \mathrm{~cm}^{-1}$ to $920 \mathrm{~cm}^{-1}$ region in all
PU/TEOS composites, assigned to $\mathrm{Si}-\mathrm{O}$ stretching vibrations of silanol $(\mathrm{Si}-\mathrm{OH})$ groups [20]. The feature at $650 \mathrm{~cm}^{-1}$ to $700 \mathrm{~cm}^{-1}$, due to symmetric stretching vibrations of $\mathrm{SiO}$ in the $\mathrm{SiO}_{4}$ tetrahedra, is more intense in the Raman spectra with the higher amount of TEOS [21].

\subsection{Water uptake}

All specimens were cut into $10 \mathrm{~mm} \times 10 \mathrm{~mm}$ pieces with $1 \mathrm{~mm}$ thickness. The samples were dried in a vacuum oven for $24 \mathrm{~h}$ and their weight was measured as $\mathrm{W}_{\mathrm{d}}$. The samples soaked in deionized water were weighed $\left(\mathrm{W}_{\mathrm{t}}\right)$ at room temperature after various immersion times up to $96 \mathrm{~h}$. Water absorption of the samples was obtained by the following relation [22]:

$$
W(\%)=\frac{W_{t}-W_{d}}{W_{d}} \times 100
$$

The average of three different readings was taken.

Fig. 9 shows the water absorption of PU/TEOS composites. Most samples were saturated after $5 \mathrm{~h}$, and they were full of water after $60 \mathrm{~h}$. Although, the PU/200 $\mu 1$ TEOS composite can absorb the highest amount of water, the $400 \mu \mathrm{l}$ TEOS and blank PU also have high capacity for absorbing water.

\subsection{Apparent and real density}

To obtain this parameter, at least, four slices of one sample were cut from different regions of the sample and their average density was measured. Division of their masses by the related volumes gives the apparent or bulk density of the sample with dimension of $\mathrm{kg} / \mathrm{m}^{3}$ or $\mathrm{g} / \mathrm{cm}^{3}$. For calculation of apparent density for porous material, 
Table 2. Calculated values of some properties of blank PU and PU/TEOS composites.

\begin{tabular}{|c|c|c|c|c|}
\hline Sample & $\mathrm{R}$ & DPS & $\begin{array}{c}\text { Apparent dens. } \\
{\left[\mathrm{kg} / \mathrm{m}^{3}\right]}\end{array}$ & Real dens. $\left[\mathrm{kg} / \mathrm{m}^{3}\right]$ \\
\hline Blank PU & 0.988 & 0.496 & 53.3 & 1145 \\
\hline PU/200 $\mu \mathrm{l}$ TEOS & 0.982 & 0.495 & 46.8 & 1148 \\
\hline PU/400 $\mu \mathrm{l}$ TEOS & 0.978 & 0.494 & 35.5 & 1153 \\
\hline PU/600 $\mu \mathrm{l}$ TEOS & 0.960 & 0.480 & 38.6 & 1159 \\
\hline PU/800 $\mu \mathrm{l}$ TEOS & 1.000 & 0.500 & 27 & 1165 \\
\hline
\end{tabular}

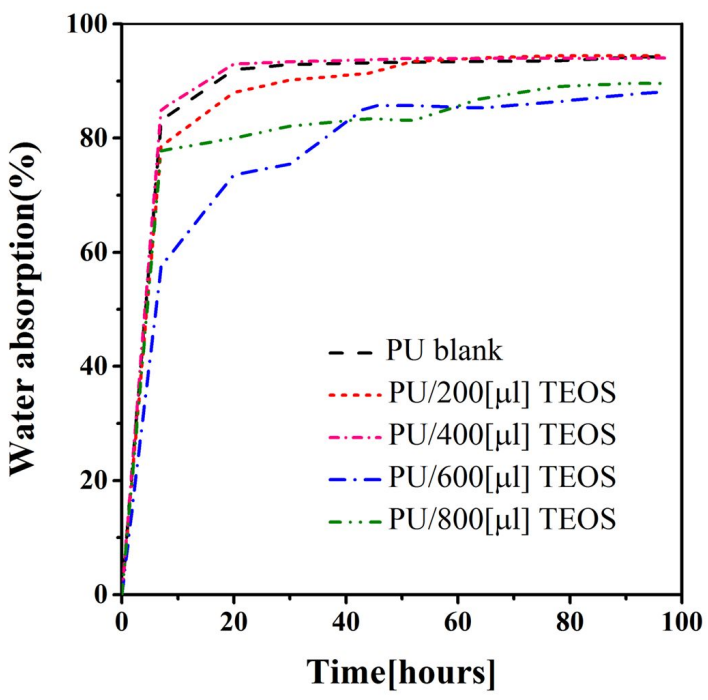

Fig. 9. Water absorption of PU foams with different TEOS contents.

Archimedes principle, the hydrostatic balance and immersion of samples in water, were used [23].

Fig. 10 shows the apparent density of PU/TEOS composites. In this image, the apparent density decreased more with higher addition of TEOS. By increasing the apparent density of the samples with equal mass, the mean cell sizes increased [9]. This can be understood from both SEM and optical microscopy images.

The true or real density of the synthesized samples was calculated by immersing them in water and recording the water displacement (pycnometry). In the density, the pores were not included; thus, dividing the masses by the volume enclosed by an envelope of water gives the true density of samples [9]. The real density of PU/TEOS foams is presented in Fig. 11.

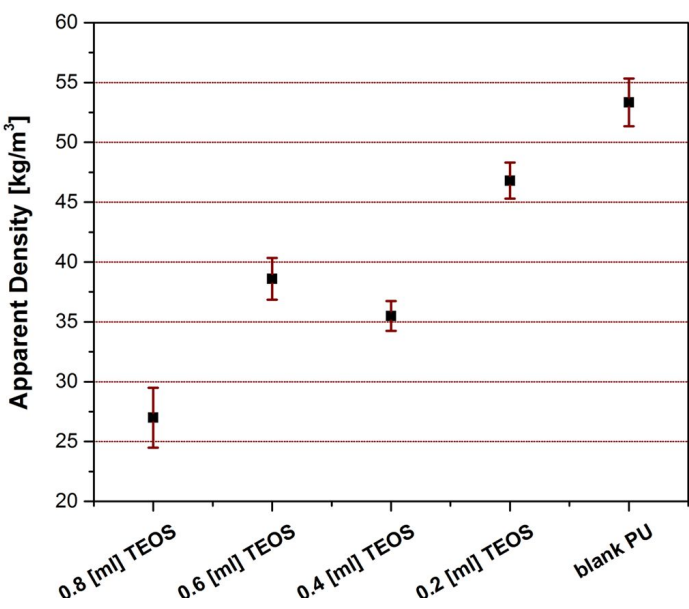

Fig. 10. Apparent density of the PU foams with different TEOS contents.

A decrease in the mean cell size of the foams causes an increase in their real density because of the higher mass in the same volume. This could be due to the creation of interconnectivity between the cells of PU foams. As shown, the real density of PU/TEOS composites is higher than the apparent density. Furthermore, it can be understood that the concentration of TEOS is an important factor in water absorption and determination of density of the samples. All apparent and real densities of the synthesized samples are shown in Table 2.

\subsection{Porosity}

The blowing agent in the chemical reaction of PU/TEOS composites produces microvoids in the cell strut which play a major factor in determination and construction of porosity. Porosity is the fraction of the total volume that is not occupied [24]. Fig. 12 shows the total, open and closed 


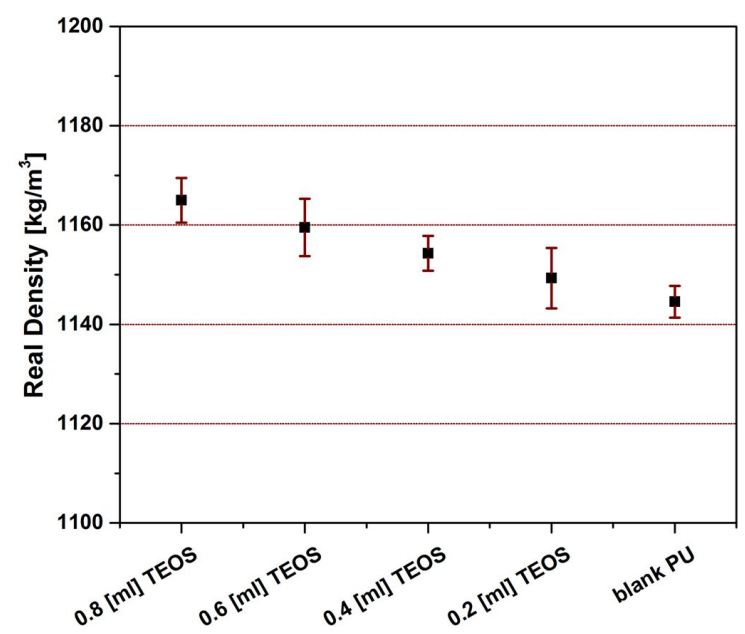

Fig. 11. The real density of the PU foams with different TEOS contents.

porosity of the blank PU and PU/TEOS composites. According to the following relation, the percentage of the total porosity of the synthesized samples was evaluated [25]:

$$
\varphi_{\text {total }}=\left(1-\rho_{\text {apparent }} / \rho_{\text {real }}\right) \times 100
$$

The $\rho_{\text {apparent }}$ and $\rho_{\text {real }}$ of the samples were previously measured. In PU foams the total porosity of PU/TEOS composites is about $2 \%$ more than in the blank PU foam. Moreover, a good sound absorber has high open porosity [25].

Using the known data for water uptake and also the time of samples saturtion, the volume of water was evaluated using the following relation:

$$
V_{\text {water }}=\left(m_{\text {saturated }}-m_{\text {dry }}\right) / \rho_{\text {water }}
$$

where: $\mathrm{m}_{\text {saturated }}$ is the mass of water saturated foam and $\mathrm{m}_{\mathrm{dry}}$ is the oven dry mass of the samples. The $\rho_{\text {water }}$ is the mass density of water. If the volume of water, $\mathrm{V}_{\text {water }}$ is divided by the original foam volume, the percentage of open porosity of the samples will be obtained. The difference between the open porosity and the total porosity is the percentage of closed porosity of the samples.

It is clear in PU composites that their open porosity reaches a maximum of up to about $18 \%$, higher than in the blank PU foam for $200 \mu$ TEOS content. Then, by increasing the TEOS loading



Fig. 12. Total, open and close porosity of the PU foams with different TEOS contents.

fraction, the open porosity of PU/TEOS composites starts to decrease. The decreasing amount of absorbed water is directly related to the rate of the open porosity in the samples. Porosity is a crucial factor for absorbing energy. Thus, it may be a promising candidate and by using different loadings of TEOS in PU, the absorbing sound may be controlled.

\section{Conclusions}

The PU hybrid was prepared by an in situ polymerization method with TEOS as a filler at high loading fractions from $200 \mu \mathrm{l}$ up to $800 \mu \mathrm{l}$. The relationships among the mentioned PU foam microstructure observed in optical micrographs and its different optical and non-optical properties were evaluated. The interaction between fillers and blank PU and thus, the effects of this interaction on optical and non-optical properties of PU composites were examined through FT-IR and Raman spectra. The FT-IR and Raman spectra were used to evaluate the bonding characteristics of PU/TEOS composites. The following conclusions can be drawn:

1. According to optical micrograph images the mean cell sizes of the foams decreased with 
increasing TEOS content from $200 \mu \mathrm{l}$ to $800 \mu \mathrm{l}$ in the blank PU.

2. In the SEM micrographs of the synthesized foams, it is observed that by adding $0 \mu \mathrm{l}$ to $800 \mu \mathrm{l}$ TEOS into the PU matrix, the cell and window sizes of the samples were significantly reduced. This decrease also caused an increase in porosity.

3. The best specimen for water uptake is PU/800 $\mu \mathrm{l}$ TEOS. Also, with an increase in the TEOS concentration in the blank PU, the amount of absorbed water decreased.

4. The results indicate that there was a maximum of $49 \%$ decrease in the apparent density of PU/800 $\mu \mathrm{l}$ TEOS composite in comparison with the blank PU foam.

5. The real density was about $2 \%$ lower than in the blank PU foam with $800 \mu \mathrm{l}$ fraction of TEOS.

6. The open porosity of the PU/200 $\mu$ TEOS foam was about $14 \%$ higher than the blank PU foam. With an increase in the amount of TEOS from $200 \mu \mathrm{l}$ to $800 \mu \mathrm{l}$, the open porosity decreased.

\section{Acknowledgements}

This work was supported by the Shahid Rajaee Teacher Training University under Contract Number 25883.

\section{References}

[1] Yildiz B., Seydibeyoglu M.O., Guner F.S., Polym. Degrad. Stab., 94 (2009), 1072.

[2] Konefą Góral J., MaŁeK A., Kluska S., JasTRZĘBSKI W., ZIMOWSKI S., JONAS S., LIS J., Mater. Sci.-Poland, 31 (2013), 476.

[3] Bistricic L., Baranovic G., Leskovac M., BaJSIC E.G., Eur. Polym. J., 46 (2010), 1975.

[4] Zhu Y., ZhaO X., WANG Z., AN D., MA Y., GUAN S., Du Y., Zhou B., Gao X., Appl. Surf. Sci., 257 (2011), 4719.

[5] Pandey S., Mishra S.B., J. Sol-Gel Sci. Technol., 59 (2011), 73

[6] Azlina H., Hasnidawani J., Norita H., Surip S., Acta Phys. Pol. A, 129 (2016), 842.
[7] Chen H., Zheng M., Sun H., JiA Q., Mater. Sci. Eng A, 725 (2007), 445.

[8] Nadafan M., Malekfar R., Dehghani Z., Acta Phys. Pol. A, 128 (2015) 29.

[9] Basirjafari S., Malekfar R., Khadem S.E., $J$. Appl. Phys., 112 (2012), 104312.

[10] Nadafan M., Malekfar R., Dehghani Z., $J$. Mater. Res., 30 (2015), 1788.

[11] Peng H.X., FAn Z., Evans J.R.J., Ceram. Int., 26 (2000), 887.

[12] Matos M.J., Dias S., Costa Oliveira F.A., $A d v$. Appl. Ceram., 106 (2007), 209.

[13] Gnyba M., Jedrzejewska-Szczerska M., KerANEN M., SUHONEN J., Proceedings of the XVII IMEKO World Congress Metrology in the $3^{\text {rd }}$ Millennium, Dubrovnik, Croatia, 273 (2003).

[14] Zhou H., Chen Y., Fan H., Shi H., Luo Z., Shi B., J. Membr. Sci., 318 (2008), 71.

[15] Sadeghi M., Semsarzadeh M.A., Barikani M., Pourafshari Chenar M., J. Membr. Sci., 376 (2011), 188.

[16] Rivera-Armenta J.L., Heinze T., MendozaMartinez A.M., Eur. Polym. J., 40, (2004), 2803.

[17] Parnell S., Min K., Cakmak M., Polymer, 44 (2003), 5137.

[18] Araujo R.C.S., Pasa V.M.D., Melo B.N., Eur. Polym. J., 41 (2005), 1420.

[19] Xia H., Song M., Soft Matter, 1 (2005), 386.

[20] Bjornstrom J., Martinelli A., Johnson J.R.T., Matic A., Panas I., Chem. Phys. Lett., 380 (2003), 165.

[21] Primera-Pedrozo O.M., Rodriguez G.D.M., Castellanos J., FeliX-Rivera H., Resto O., HernandeZ-Rivera S.P., Spectrochim. Acta A, 87 (2012), 77.

[22] Bai C.Y., Zhang X.Y., Dai J.B., Zhang C.Y., Prog. Org. Coat., 59 (2007), 331.

[23] NADAFAN M., MALEKFAR R., IZADi-DARBANDI A., Adv. Mater. Res., 829 (2014), 30.

[24] TORRES-SANCHEZ C., CORNEY J.R., Ultrason. Sonochem., 15 (2008), 408.

[25] Ryszkowska J.L., Auguscik M., Sheikh A., BocCACCINI A.R., Compos. Sci. Technol., 70 (2010), 1894. 